\title{
sciforum
}

\section{Pregnancy Outcomes of Three Different Sources of Embryos During Early Rescue-ICSI}

\author{
Kun Liu ${ }^{a}$, César Martin Plagaro ${ }^{b}$, Bairong Shen $^{c}$ \\ ${ }^{a}$ Reproductive Medicine Center of Lanzhou University First Hospital, Lanzhou, 730030, China \\ ${ }^{b}$ Biochemistry and Molecular Biology Department, University of the Basque Country UPV/EHU, \\ 48940, Leioa, Biscay, Spain. \\ ${ }^{C}$ Institutes for Systems Genetics, West China Hospital, Sichuan University, Chengdu, 610000, China
}

\begin{tabular}{|l|l|}
\hline Graphical Abstract & $\begin{array}{l}\text { Abstract } \\
\text { BACKGROUND : This retrospective study aimed } \\
\text { to investigate pregnancy outcomes when transferred } \\
\text { three different sources embryos during early rescue } \\
\text { ICSI. } \\
\text { MATERIAL AND METHOD: A total of } 805 \\
\text { infertility cases were included. On the third day after } \\
\text { insemination, 615 cases transferred with one to three } \\
\text { embryos. The pregnant rate, abortion rate and live } \\
\text { birth rate were compared in three groups. } \\
\text { RESULTS: 1)Pregnant group with younger female } \\
\text { age, less starting gonadotropin dose, fertilization and } \\
\text { embryonic score were better. 2)Pregnant rate, early } \\
\text { abortion rate and ectopic pregnancy rate were the } \\
\text { lowest in only ICSI sources embryo. Multiple } \\
\text { pregnancy rate and the birth rate of low weight } \\
\text { babies at term was lower in the transferred both IVF } \\
\text { and ICSI sources embryo group. (3)The sex ratio of } \\
\text { the newborn in the three groups were different } \\
\text { significantly, IVF with more girl, ICSI with more } \\
\text { boy, and IVF/ICSI group was the most balanced. } \\
\text { 4)Both cleavage rate and good quality embryo rate } \\
\text { were the predictors of clinical pregnancy and live } \\
\text { birth. } \\
\text { CONCLUSIONS: Using the early rescue ICSI } \\
\text { based on short-term insemination was helpful to } \\
\text { increase the utilization rate of the embryo, and } \\
\text { improve the clinical pregnancy outcome. While more } \\
\text { researches are needed on the safety of offspring. } \\
\text { Key Words: Fertilization failure, Early rescue ICSI, } \\
\text { Pregnancy outcomes }\end{array}$ \\
\hline
\end{tabular}

\section{References}

1. Chen C, Kattera S: Rescue ICSI of oocytes that failed to extrude the second polar body $6 \mathrm{~h}$ post-insemination in conventional IVF. Human reproduction. 2003, 18(10):2118-2121. 
2. $\quad$ Barlow P, Englert Y, Puissant F, Lejeune B, Delvigne A, Van Rysselberge M, Leroy F: Fertilization failure in IVF: why and what next? Human reproduction. 1990, 5(4):451-456.

3. Chen L, Xu Z, Zhang N, Wang B, Chen H, Wang S, Sun H: Neonatal outcome of early rescue ICSI and ICSI with ejaculated sperm. Journal of assisted reproduction and genetics. 2014, 31(7):823-828.

4. He Y, Liu H, Zheng H, Li L, Fu X, Liu J: Effect of early cumulus cells removal and early rescue ICSI on pregnancy outcomes in high-risk patients of fertilization failure. Gynecological endocrinology : the official journal of the International Society of Gynecological Endocrinology. 2018, 34(8):689-693.

5. Huang B, Qian K, Li Z, Yue J, Yang W, Zhu G, Zhang H: Neonatal outcomes after early rescue intracytoplasmic sperm injection: an analysis of a 5-year period. Fertility and sterility 2015, 103(6):1432-1437 e1431.

6. Veeck LL: Fertilization and early embryonic development. Current opinion in obstetrics \& gynecology. 1992 , 4(5):702-711.

7. Gardner DK, Lane M, Stevens J, Schlenker T, Schoolcraft WB: Blastocyst score affects implantation and pregnancy outcome: towards a single blastocyst transfer. Fertility and sterility. 2000, 73(6):1155-1158.

8. Floehr J, Dietzel E, Neulen J, Rosing B, Weissenborn U, Jahnen-Dechent W: Association of high fetuin-B concentrations in serum with fertilization rate in IVF: a cross-sectional pilot study. Human reproduction. 2016, 31(3):630-637.

9. Zhang L, Jiang XH: [Ultrastructure of unfertilized human oocytes and undivided human zygoytes]. Sichuan da xue xue bao Yi xue ban = Journal of Sichuan University Medical science edition. 2010, 41(5):810-813.

10. Nakamura T, Iwase A, Bayasula B, Nagatomo Y, Kondo M, Nakahara T, Takikawa S, Goto M, Kotani T, Kiyono T et al: CYP51A1 induced by growth differentiation factor 9 and follicle-stimulating hormone in granulosa cells is a possible predictor for unfertilization. Reproductive sciences. 2015, 22(3):377-384.

11. Ming L, Liu P, Qiao J, Lian Y, Zheng X, Ren X, Huang J, Wu Y: Synchronization between embryo development and endometrium is a contributing factor for rescue ICSI outcome. Reproductive biomedicine online. 2012, 24(5):527-531.

12. Raziel A, Friedler S, Strassburger D, Komarovsky D, Kasterstein E, Ron-el R: Reproductive performance of patients undergoing intracytoplasmic sperm injection with $100 \%$ implantation rate. Journal of assisted reproduction and genetics. 2000, 17(7):379-384.

13. Hwang SY, Jeon EH, Kim SC, Joo JK: Clinical factors that affect the pregnancy rate in frozen-thawed embryo transfer in the freeze-all policy. Yeungnam University journal of medicine 2020, 37(1):47-53.

14. Ubaldi F, Rienzi L: Morphological selection of gametes. Placenta. 2008, 29 Suppl B:115-120.

15. Kahraman S, Yakin K, Donmez E, Samli H, Bahce M, Cengiz G, Sertyel S, Samli M, Imirzalioglu N: Relationship between granular cytoplasm of oocytes and pregnancy outcome following intracytoplasmic sperm injection. Human reproduction. 2000, 15(11):2390-2393.

16. Jin H, Shu Y, Dai S, Peng Z, Shi S, Sun Y: The value of second polar body detection 4 hours after insemination and early rescue ICSI in preventing complete fertilisation failure in patients with borderline semen. Reproduction, fertility, and development. 2014, 26(2):346-350.

17. Simopoulou M, Giannelou P, Bakas P, Gkoles L, Kalampokas T, Pantos K, Koutsilieris M: Making ICSI Safer and More Effective: A Review of the Human Oocyte and ICSI Practice. In vivo 2016, 30(4):387-400.

18. Rubino P, Vigano P, Luddi A, Piomboni P: The ICSI procedure from past to future: a systematic review of the more controversial aspects. Human reproduction update. 2016, 22(2):194-227.

19. Liu W, Liu J, Zhang X, Han W, Xiong S, Huang G: Short co-incubation of gametes combined with early rescue ICSI: an optimal strategy for complete fertilization failure after IVF. Human fertility. 2014, 17(1):50-55. 